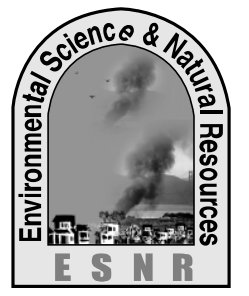

J. Environ. Sci. \& Natural Resources, 6(1): 107 - 112, 2013

ISSN 1999-7361

\title{
Effects of Earthquake on Urbanization in Dhaka City
}

\author{
M. S. Islam ${ }^{1}$, N. Sultana ${ }^{1}$, N. Bushra ${ }^{1}$, L. N. Banna ${ }^{1}$, T. R. Tusher ${ }^{1}$ and M. A. Ansary ${ }^{2}$ \\ ${ }^{1}$ Department of Environmental Science and Resource Management, Mawlana Bhashani Science and \\ Technology University, Tangail-1902, Bangladesh \\ ${ }^{2}$ Department of Civil Engineering, Bangladesh University of Engineering and Technology, Dhaka-1000, \\ Bangladesh
}

\begin{abstract}
Recent earthquakes with low to moderate magnitude very close to Dhaka are certainly indications of its earthquake source and vulnerability. The study was conducted to bring out the present earthquake vulnerability status of 10 wards, out of 91 wards, in Dhaka and to assume the probable loss of lives and property by studying the previous records in the city and getting respondents opinion about it. The ward no. 15 show higher building density with older age of building i.e. more than 30 years of age, and present more unreinforced buildings than other wards which might be the cause of increased vulnerability to earthquake. Among the 10 wards, the ward no. 13 and 17 are more vulnerable to earthquake due to highest soft storey buildings, heavy overhang, presence of short columns and poor physical condition of buildings. The result of the survey found that more than half $(64 \%)$ of the respondents considered Dhaka city as the highly vulnerable to earthquake because of most of the infrastructures were built without maintaining the building code and also without keeping proper spaces among them. Besides these, $40 \%$ respondents stated that the impact would be obvious on life as there would not be enough time to escape people from the high rise buildings to safer places during the earthquake. Almost all the respondents $(86 \%)$ consider that the southern part of Dhaka city is more vulnerable than other parts of the city due to the increasing urbanization and poorly structured old buildings.
\end{abstract}

Key words: Building,, Dhaka city, Earthquake, Urbanization, Vulnerability

\section{Introduction}

Bangladesh lies in the Burma basin, which was formed by the continent-continent collision of India to the north, and sub-duction of ocean crust beneath the Burma continental crust to the east. The country has a long history of seismic activity as it is surrounded by the regions of high seismicity, which include the Himalayan Arc and Shillong Plateau in the north, the Burmese Arc (DMB, 2006). Geographically Bangladesh is located close to the boundary of two active Plates: the Indian Plate in the west and Eurasian Plate in the east and north. The historical seismic data and recent seismic activities in Bangladesh and adjoining areas indicate that Bangladesh is at seismic risk. Records of earthquakes show that Bangladesh and surrounding areas experienced at least 1000 earthquakes having magnitude greater than or equal to 4 in the last 100 years (Alam et al., 2011). It is estimated that about $60 \%$ of world-wide casualties associated with natural disasters are caused by earthquakes (Agarwal and Shrikhande, 2007). The most important seismic hazards are considered as shaking and ground rupture created by earthquakes, principally resulting in more or less severe damage to building and other rigid structures (Kramer, 2008). As most of the buildings in Bangladesh are still being constructed without consulting an engineer or an architect, the builders are thus leaving them greatly vulnerable to earthquake which is thought to be causing huge human casualties once even a medium scale earthquake strikes the city (Ansary, 2005).
Dhaka city, the capital of Bangladesh and the most densely mega-city of the world, is largely an alluvial plain consisting of fine sand and silt deposits with shallow ground water table (Islam et al., 2010). Over the past decades, urbanization in Dhaka has been rapidly taking place without proper guidance. As a result of rapid urbanization in the city, the population is increasing rapidly and the buildings are also growing in an unplanned way to accommodate the dwellers in the city. The infrastructures and life safety in Dhaka against seismic hazard are now a burning concern as the Earthquake Disaster Risk Index has placed Dhaka among the 20 most vulnerable cities in the world. Micro-seismicity data supports the existence of at least four earthquake source points in and around Dhaka (Ahmed and Ahmed, 2010).

As Dhaka belongs to an active seismic zone, most of the buildings in Dhaka city are thought to be vulnerable to seismic hazard because of their poor quality construction and no quality control measures (Ansary, 2005). Moreover, Dhaka is moving 30.6 $\mathrm{mm}$ /year in the direction of north-east. In addition, the rate of strain accumulation is relatively high in and around Dhaka. It may precipitate in an earthquake of magnitude 6.8 in the event of the release of accumulated strain (Khan and Hussain, 2005). For these reasons, vulnerability to earthquakes is increasing in the city and life safety is becoming questionable day by day. Considering these views in mind, the study was conducted to find out the earthquake vulnerability of Dhaka city and also to 
know the people's perception about the effects of earthquakes on the city.

\section{Materials and Methods}

\section{Study area}

Dhaka, the capital of Bangladesh, was selected as the location of the study. Dhaka is located on the banks of the Buriganga River. Dhaka and its surrounding metropolitan area has a total population of 11 million, spread over a total area of 815.85 sq. km., with a population density of 14,608 persons per sq. $\mathrm{km}$. The city has become the $7^{\text {th }}$ most populous city in the world and considered as the world's most densely mega-city (Banglapedia, 2008). Among the 91 wards of the city, 10 wards were selected as the study area in purpose of determining the impact of earthquake on Dhaka city and awareness among people about its impact.

\section{Data collection}

The primary data were collected through a questionnaire survey where questions covered vulnerability to earthquake, its impacts on building and Dhaka city, etc. It is believed that closed-ended questions probably limit the responses to the topics (Fraenkel and Wallen, 1996). Thus, the questionnaire was decorated with both the closed and open-ended questions to gain the maximum possible results. Different types of secondary data, which included the area, building number and building density of the corresponding wards, were collected focusing the objective of the study. In addition, building age and their visible physical conditions (poor, average or good) in respect of wards were also collected. These data were collected from the Comprehensive Disaster Management Program (CDMP). Besides these, other relevant information on the Community based
Earthquake Risk Management and how the infrastructures can be built in a safe way were also collected from Asian Disaster Preparedness Center (ADPC) and a shelter safety handbook of red cross, respectively.

\section{Data analysis}

Data were collected during the period of January to July, 2012. The statistical measures such as number and percent distribution were used for describing the variables of the study. Both the Statistical Package for Social Science (SPSS version 14.0) and Microsoft Office Excel 2003 were employed to analyze the questionnaire data.

\section{Results and Discussions}

Buildings respond to ground shaking in earthquakes due to high building densities, lack of proper maintenance (Emergency response), more ages of building and many other issues which are related to earthquake vulnerability of building. Moreover, as a result of the rapid urbanization and over population in urban areas, buildings are growing in an unplanned way to accommodate people in the Dhaka city. Thus, earthquake vulnerability of Dhaka city is increasing day by day. CDMP (2009) represents the status of building in the Dhaka city of study area (Table 1), where the ward no. 15 shows higher building density. Only three wards (ward no. 1, 6, and 13) have higher emergency responses (fire-brigade, police stations), whereas others reflect very worse conditions. Most of the building of the ward no. 15 are older i.e. more than 30 years of age (Table 1). Hays et al. (1998) found that with the passage of time, buildings loss their lateral resistance and turn into more vulnerable to an earthquake. For this reason, the buildings of the ward no. 15 might be more vulnerable to earthquake.

Table 1. Status of buildings in the study area

\begin{tabular}{|c|c|c|c|c|c|c|}
\hline \multirow{2}{*}{$\begin{array}{l}\text { Ward } \\
\text { No. }\end{array}$} & \multirow{2}{*}{$\begin{array}{l}\text { Building } \\
\text { Number }\end{array}$} & \multirow{2}{*}{$\begin{array}{l}\text { Building Density } \\
\qquad\left(\mathrm{No} . / \mathrm{Km}^{2}\right)\end{array}$} & \multirow{2}{*}{$\begin{array}{c}\text { Emergency } \\
\text { response }\end{array}$} & \multicolumn{3}{|c|}{ Building age (year) } \\
\hline & & & & $<\mathbf{1 0}$ & $10-30$ & $>30$ \\
\hline 01 & 8182 & 978 & 6 & 1685 & 2874 & 3634 \\
\hline 06 & 10452 & 3290 & 7 & 2159 & 2722 & 5585 \\
\hline 08 & 6380 & 1832 & 2 & 1339 & 1736 & 3312 \\
\hline 13 & 12114 & 1477 & 7 & 2982 & 3677 & 5447 \\
\hline 15 & 13141 & 6103 & 3 & 2498 & 2784 & 7847 \\
\hline 16 & 7923 & 1043 & 2 & 1956 & 2366 & 3630 \\
\hline 17 & 4467 & 1540 & 1 & 3155 & 3492 & 5732 \\
\hline 21 & 6482 & 765 & 3 & 1552 & 1900 & 3025 \\
\hline 48 & 4981 & 578 & 2 & 1042 & 1588 & 2348 \\
\hline 58 & 4692 & 616 & 2 & 1142 & 1412 & 2142 \\
\hline
\end{tabular}

Types of building structures

The higher percentage goes towards the others types of buildings which include the masonry type and light reinforced concrete buildings, than reinforced concrete buildings (Fig. 1), because people thought both the masonry buildings and light reinforced concrete buildings are more reliable against various types of disasters and have sustainable utilization; but 
it is also found that low quality or poor construction may also be deadly for dweller. The highest number of masonry buildings was in the ward no. 15 and the unreinforced buildings were almost higher than 9000 in each ward (Fig. 1). The masonry structures are more vulnerable during earthquake, while modern engineering concrete-framed buildings are generally safer than non engineering infrastructures. Malladi (2012) said "Earthquakes don't kill people, buildings do". Thus, the people who prefer the masonry buildings are more vulnerable to earthquake or building collapse.

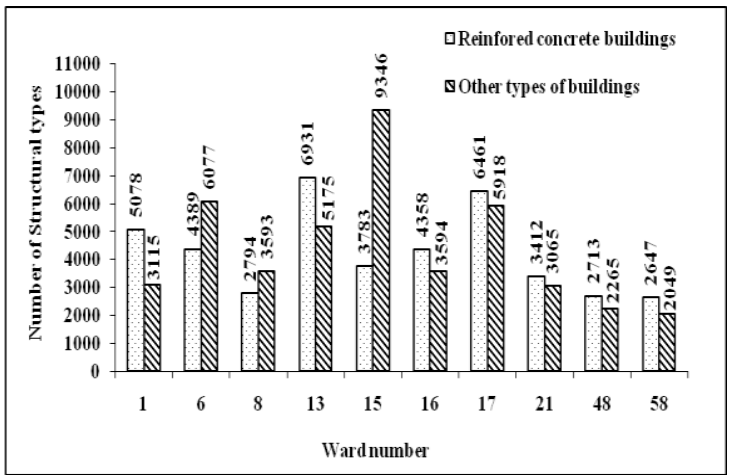

Fig. 1. Types of building structures in the study area

\section{Soft storey buildings}

A soft storey is one in which the lateral stiffness is less than $70 \%$ of that in the storey above or less than $80 \%$ of the average stiffness of the three storey above. From the study, the highest number of soft storied buildings was found in the ward no. 13, i.e. Kazipara, Shewrapara and Monipur were the most vulnerable areas. In addition, the number of soft storied buildings was 3667 in the ward no. 17 which was comparatively less than the ward no. 13. Besides these, there were not very large differences among the wards 1, 6, 15 and 16. However, the lowest numbers of soft storied buildings were found in the ward no. 58 (Azimpur, Nawabgonj, and Companyghat) and in 48 (Rayerbazar, Bashbari) (Fig. 2). CDMP (2009) stated that the soft storey buildings exhibit a less safe behaviour than the similar regular structures during moderate and severe earthquake.

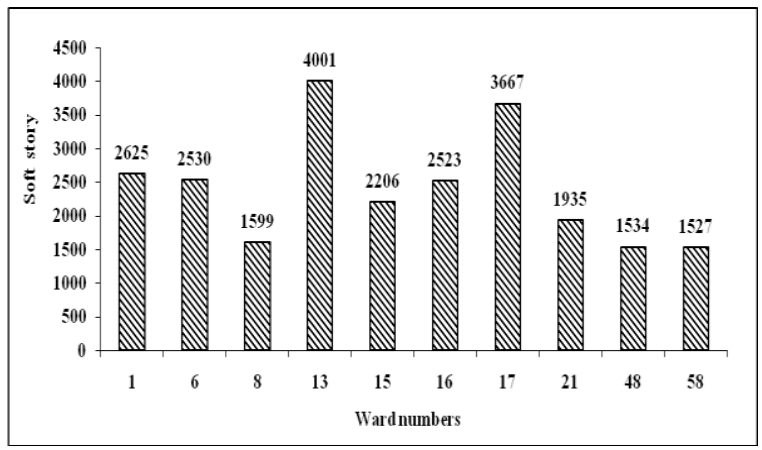

Fig. 2. Soft storey buildings in the study area

\section{Heavy overhang buildings}

It is found from the study that the highest number of heavy overhang in buildings 3086 and 2854 was in 13 and 17 no. wards, respectively, and about above 1500 heavy overhang in buildings was found in about 5 wards. This vulnerability factor is almost same in the 48 and 58 no. wards. However, the number of heavy overhang in buildings 1239 was found in the ward no. 8 which was relatively lower than that in the ward no. 1 and 6 (Fig. 3). Heavy overhanging floors in multistorey buildings lead to plan irregularity. McCrum (2012) found that the affect of strength eccentricity on the seismic response of plan irregular structures needs further investigation and increasing the strength of a lateral force resisting element in the infrastructure.

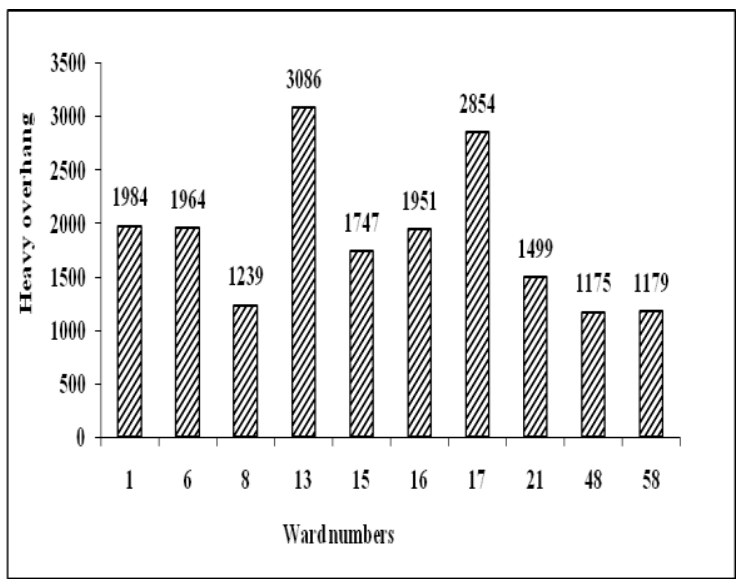

Fig. 3. Heavy overhang of buildings in the study area

\section{Presence of short columns buildings}

Short columns can be created by the arrangement of infill walls or other non-structural, architectural members. The result showed that the highest number of buildings with short column 2581 and 2406 was found in the ward no. 13 and 17, respectively. The ward no. 6 and 16 have almost same numbers of such kind of factor. In case of 48 and 58 no. wards, they have lowest numbers of short column buildings. Though the population and building density in 15 no. ward are higher than that of in 16 , the short column is relatively less in this ward (Fig. 4). Due to the increase in stiffness, the columns share more flexural moment and this causes the increase in shear forces. Therefore, these columns usually sustain heavy damage during strong earthquake (CDMP, 2009). 


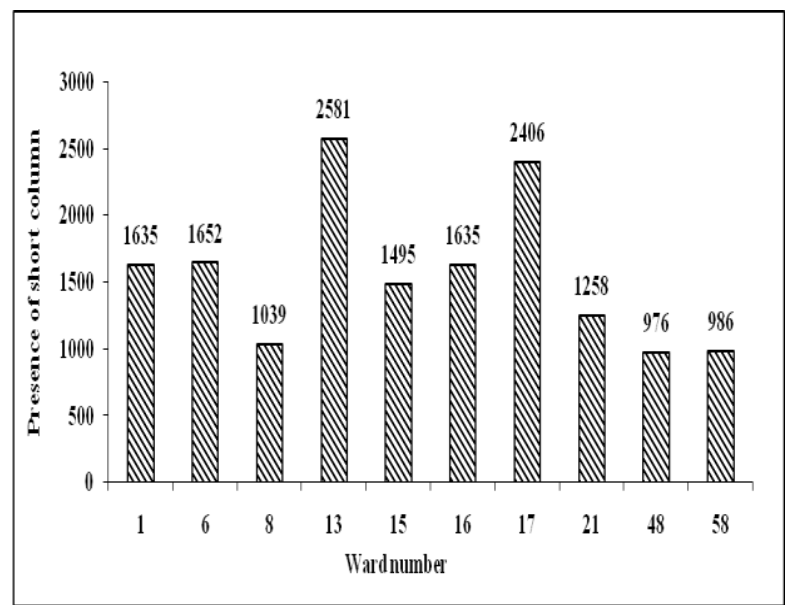

Fig. 4. Number of short columns of the building in corresponding wards

\section{Visible physical conditions of buildings}

It is found that most of the buildings are in poor condition. In the ward no. 13, the highest number of poorly conditioned buildings is present, whereas comparatively good quality buildings are observed in the ward no. 15 (Fig 5). In this case, poor condition means buildings having soft storey, heavy overhang and the land is filling with sand or clay which are more vulnerable to earthquake.

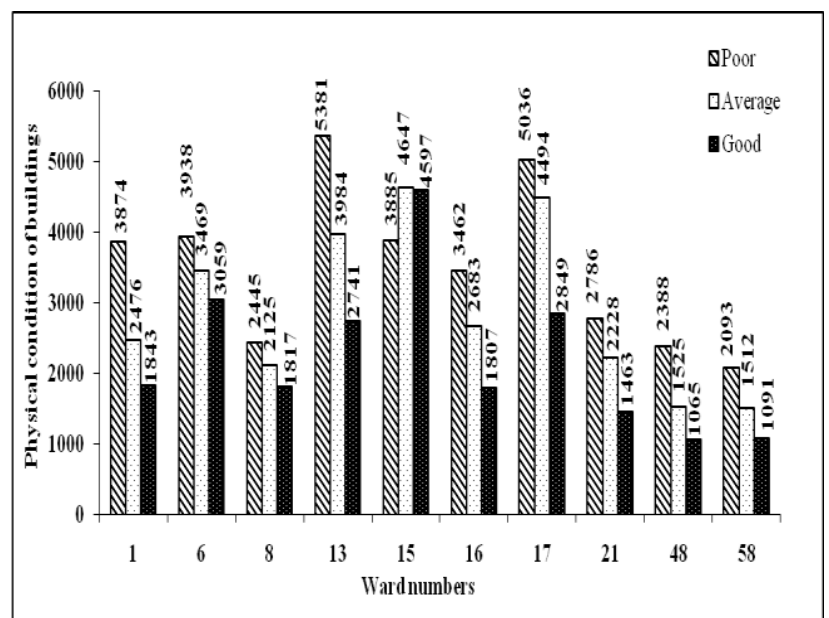

Fig. 5. Physical condition of buildings observed ward wise in the study area

\section{Respondent's perception}

A questionnaire survey was completed on the fifty specialists who were related to the profession like designers, planners, engineers and contractor to know about earthquake vulnerability and its impacts on the Dhaka city. The result showed that the respondents had better knowledge about earthquake vulnerability with its impacts. More than half of the respondents (64\%) stated that it was highly vulnerable as most of the infrastructures were built without maintaining the building code and also without keeping proper spaces among buildings, whereas only $4 \%$ people considered that Dhaka was less vulnerable to earthquake because they thought that the buildings were built properly, and $24 \%$ contemplated that Dhaka was moderately vulnerable to earthquake because historically it was not an earthquake-prone district and there were necessary emergency response present in the area (Table 2). Among the respondents, almost half (40\%) stated that the impact would be much on life as there would be no enough time to escape from the high rise buildings to safer places during an earthquake, while $20 \%$ stated that the impacts would be much on private property because people did not develop their properties with proper care and did not use earthquake resistant technologies during construction, and $36 \%$ believed that the impact would be mostly on infrastructure because the infrastructures which were built haphazardly and densely without maintaining proper guidance. Only 4\% thought that the impact would be on garden and forests as they thought that these would be damaged because of shaking earth surface and sudden falling of the trees (Table 2).

Among of the respondents, only $12 \%$ considered that their buildings were resistant of earthquake as they were conscious about the foundation, 56\% respondents stated that the resistance of their buildings were medium as they thought that their buildings were strong enough though they did not build their buildings following earthquake resistant technology, whereas $32 \%$ people stated that their buildings were build under very poor construction and management (Table 2). It is viewed from the study that more than $50 \%$ consider that southern part of the Dhaka city are more vulnerable than other parts of the city as the southern part is the most dense part of the city and both the age and quality of the buildings are very poor, while only $14 \%$ respondents think that the northern part of the city are vulnerable because of less emergency response present there (Table 2). 
Table 2. Respondent's perception about earthquake

\begin{tabular}{|c|c|c|c|c|}
\hline Sl. No. & Phenomenon & Contents & Total no. & Percentage $(\%)$ \\
\hline \multirow[t]{4}{*}{1} & \multirow{4}{*}{$\begin{array}{l}\text { Thinking about earthquake } \\
\text { vulnerability }\end{array}$} & High & 32 & 64 \\
\hline & & Moderate & 12 & 24 \\
\hline & & Less & 2 & 4 \\
\hline & & No idea & 4 & 8 \\
\hline \multirow[t]{4}{*}{2} & \multirow{4}{*}{$\begin{array}{l}\text { Probable impacts of earthquake on } \\
\text { different points }\end{array}$} & Property & 10 & 20 \\
\hline & & Life & 20 & 40 \\
\hline & & Infrastructure & 18 & 36 \\
\hline & & Garden and forest & 2 & 4 \\
\hline \multirow[t]{3}{*}{3} & \multirow{3}{*}{$\begin{array}{l}\text { Level of earthquake resistance } \\
\text { houses or offices }\end{array}$} & High & 6 & 12 \\
\hline & & Medium & 28 & 56 \\
\hline & & Low & 16 & 32 \\
\hline \multirow[t]{2}{*}{4} & \multirow[t]{2}{*}{ Vulnerable part of Dhaka city } & Northern part & 7 & 14 \\
\hline & & Southern part & 43 & 86 \\
\hline
\end{tabular}

At present earthquake risk of Dhaka city has been one of the most burning topics to discuss about. An earthquake with a moderate to high intensity can cause an immense and destructive impact on both the property and people of the city. Among the 10 wards, the ward no. 15 has higher building density and also ancient building those are more than 30 years of age. More unreinforced buildings are also present in the ward no. 15 than other wards which might be the cause of increased vulnerability to earthquake in the Dhaka city. The wards no. 13 and 17 are also vulnerable to earthquake due to highest soft storey buildings, heavy overhang, presence of short columns and poor physical condition of buildings which are responsible for more earthquake vulnerability. It is clear from the survey that most of the respondents considere that the Dhaka city is highly vulnerable to earthquake as most of the infrastructures were built without maintaining the building code and without keeping proper spaces among buildings. More than fifty percent respondents stated that the southern part of the city is more vulnerable than other parts due to rapid urbanization and poorly structured old buildings. In order to recovery the problem, vulnerability analysis of the buildings should be conducted in a regular interval to determine the potential threat to the area, and also the Geographic Information System (GIS) and geosciences applications may be developed to improve the seismic safety practices.

\section{Acknowledgements}

The authors express their sincere appreciation to various personnel's of DCC (Dhaka City Corporation) and CDMP (Comprehensive Disaster Management Program) for their kind support and assistance during the collection of secondary information's related earthquake and urbanization in Dhaka city. Thanks also goes to the contractors, engineers, designers, planners and specialists for their kind support and sincere assistance to collect the necessary information's during the study period.

\section{References}

Agarwal, P. and Shrikhande, M. 2007. Earthquake resistant design of structures, Prentice-hall, India, 3-41.

Ahmed, S. and Ahmed, H. T. 2010. Disaster risk and risk mitigation in Dhaka other cities, UNICEF, Dhaka, Bangladesh.

Alam, M. S.; Sakib, N. and Mumtaz, M. 2011. Seismic loss assessment of Dhaka for scenario earthquakes using a displacement-based method.

Ansary, M. A. 2005. Recent earthquake related activities in Bangladesh, Paper presented at seminar on Tsunami and Seismic Risk Action for Bangladesh, Dhaka, Bangladesh.

Banglapedia. 2008. Dhaka city, National Encyclopaedia of Bangladesh, Asiatic Society of Bangladesh.

CDMP (Comprehensive Disaster Management Program). 2009. Vulnerability of Dhaka, Chittagong and Sylhet City Corporation Area, Dhaka, Bangladesh assessment.

DMB (Disaster Management Bureau). 2006. Periodic briefing session on earthquake disaster management, Dhaka, Bangladesh.

DRMP (Disaster Risk Management Profile). 2006. Map of Dhaka City Corporation, Dhaka, Bangladesh.

Fraenkel, J. R. and Wallen, N. E. 1996. How to design and evaluate research in education, 
McGraw-Hill Publishers Ltd., New York, USA.

Hays, W.; Mohammadioun B. and Mohammadioun, J. 1998. Seismic zonation: A framework for linking earthquake risk assessment and earthquake risk management (Monograph), Quest Editions Presses Academiques.

Islam, M. S.; Hossain, M. T.; Ameen, S. F.; Hoque E. and Ahamed, S. 2010. Earthquake induced liquefaction vulnerability of reclaimed areas of Dhaka, Journal of Civil Engineering (IEB), 38(1): 65-80.

Khan, A. A. and Hussain, M. S. 2005. Recurrence of 1885 Bengal earthquake and hazard vulnerability status of Dhaka Metropolitan City, Bangladesh, Oriental Geography, 49(2): 205-216.
Kramer, S .L. 2008. Geotechnical earthquake engineering, Dorling Kindersley, India, 1-18.

Malladi, V. T. 2012. Earthquake building vulnerability and damage assessment, MS thesis, Indian Institute of Remote Sensing of Indian Space Research Organisation, Department of Space, Government of India and the Faculty of Geo-Information Science and Earth Observation of the University of Twente, Dehradun, India.

McCrum, D. P. 2012. Seismic analysis of braced plan irregular structures using Hybrid Testing and Numerical Modelling, Department of Civil, Structural and Environmental Engineering, University of Dublin, Trinity College. 